\title{
Aktivisme Hoofdbestuur Muhammadiyah Bagian PKO di Yogyakarta Sebagai Representasi Gerakan Pelayanan Sosial Masyarakat Sipil (1920-1931)
}

\section{GHIFARI YURISTIADHI}

Universitas Gadjah Mada

ghifariyuristiadhi@gmail.com

\section{ABSTRACT}

Penolong Kesengsaraan Oemoem (PKO) was one of the four first organizational divisions formed by Hoofdbestuur Muhammadiyah in 1920. In particular, as the name suggests, this division was expected to design, manage, and develop Muhammadiyah's social services. Chaired by Hadji Soedjak, in the period 19201931, the PKO had opened a health clinic (1923) and founded the poor house (1923) and orphanages (1931). Muhammadiyah was an organization formally recognized by the Dutch colonial government since 1914, and therefore, the social activities carried the PKO of Hoofdbestuur Muhammadiyah can be seen as a movement of civil society outside the state. It can be said that Muhammadiyah's widespread social services represented by $\mathrm{PKO}$, became a resource for Muhammadiyah to put its bargaining position in face of the Dutch colonial government, and Kasultanan Yogyakarta and that of Kadipaten Pakualaman. Muhammadiyah provided the social services to the society when the states absent to put on it.

Keywords: Muhammadiyah, $\mathrm{PKO}$ section, social services, civil society

\section{ABSTRAK}

Bagian Penolong Kesengsaraan Oemoem (PKO) adalah salah satu dari empat bagian pertama yang dibentuk Hoofdbestuur Muhammadiyah pada 1920. Secara khusus, sesuai dengan namanya, bagian ini diharapkan dapat mendesain, mengelola, dan mengembangkan pelayanan sosial Muhammadiyah. Diketuai oleh Hadji Soedjak, dalam kurun 1920-1931, Bagian PKO telah membuka poliklinik kesehatan (1923) serta mendirikan rumah miskin (1923) dan rumah yatim (1931). Muhammadiyah adalah organisasi yang secara formal diakui oleh Pemerintah Kolonial Belanda 
sejak 1914, maka aktivitas sosial yang dilakukan Bagian PKO Hoofdbestuur Muhammadiyah bisa dilihat sebagai gerakan masyarakat sipil di luar negara. Aktivitas pelayanan sosial bagian PKO menunjukkan posisi tawar tersendiri bagi Muhammadiyah di mata Pemerintah Kolonial Belanda, Kasultanan Yogyakarta dan Kadipaten Pakualaman. Muhammadiyah memiliki pelayanan sosial untuk masyarakat ketika negara absen menyediakan.

Kata kunci: Muhammadiyah, Bagian PKO, pelayanan sosial, masyarakat sipil

\section{Pendahuluan}

Ada dua hal kontradiktif yang terjadi menjelang tahun 1920 yang menerpa dua organisasi Islam yang cukup dinamis dalam satu dekade terakhir di Yogyakarta, yakni Serikat Islam dan Muhammadiyah. Serikat Islam, organisasi massa Islam terbesar di Hindia Belanda yang berdiri pada 1913 oleh HOS Tjokroaminoto sebagai kelanjutan dari Serikat Dagang Islam yang didirkan oleh Haji Samanhudi di Solo pada 1911, semakin disibukkan dengan aktivitas propaganda untuk kalangan petani dan buruh. Serikat Islam mengadvokasi petani dan buruh perkebunan yang dilanda kelangkaan bahan pangan yang mulai dirasakan ketika itu. Propaganda dan advokasi yang berujung dengan pemogokan buruh di banyak tempat tersebut memang menjadi gerakan utama Cental Serikat Islam (CSI), pengurus pusat Serikat Islam yang dideklarasikan pada 1916 di Bandung, dan digerakkan di seluruh Hindia Belanda. ${ }^{1}$

Puncak dari surutnya dukungan masyarakat Hindia-Belanda adalah meletusnya peristiwa "Afdeeling B" yang menyeret nama-nama para petinggi Serikat Islam. Peristiwa tersebut adalah perlawanan masyarakat Cimareme, Garut yang dipimpin oleh Haji Hasan yang menolak pembelian sepihak padi oleh Wedana pada 1919, lokasi tersebut juga merupakan basis Serikat Islam. Perlawanan tersebut berakhir dengan ditembak dan dipenggalnya Haji Hasan dan beberapa pengikutnya oleh pemerintah kolonial sebagai gertakan bagi orang yang berani melawan pemerintah kolonial. Banyak dari para petinggi Serikat Islam yang ditangkap. Sosrokardono, salah satu pengurus CSI dihukum empat tahun, sedangkan Tjokroaminoto, pendiri sekaligus ketua CSI, juga ditahan karena dianggap memberikan keterangan palsu terkait peristiwa "Afdeeling B". Ini menjadi antiklimaks Serikat Islam karena banyak anggotanya yang memilih keluar dan takut untuk berafiliasi dengan Serikat Islam, termasuk di Yogyakarta yang juga menjadi salah satu basis Serikat Islam. ${ }^{2} \mathrm{Hal}$ ini berimbas pada berkurangnya loyalitas dan sokongan ataupun derma kepada organisasi dari masyarakat.

Dalam momentum yang lain, semenjak membentuk bagian Penolong 
Kesengsaraan Oemoem (PKO) yang diresmikan ketika Rapat Anggota Istimewa Muhammadiyah pada 18 Juni 1920, Muhammadiyah, organisasi sosial yang didirikan oleh KH. Ahmad Dahlan pada 1912, justru semakin fokus dalam membangun pelayanan-pelayanan sosialnya. Bersamaan dengan berdirinya bagian PKO itu, Hooftbestuur Muhammadiyah juga memiliki bagian Tabligh yang berkonsentrasi pada penyiaran Islam, bagian Pengajaran yang berfokus pada pengaturan operasional sekolah Muhammadiyah termasuk memenuhi hak-hak guru, dan bagian Pustaka yang bertugas menyebarkan informasi kegiatan Muhammadiyah dan juga syiar dengan penerbitan majalah bulanan. ${ }^{33}$ Di saat SI mulai kehilangan kepercayaan dari masyarakat, justru Muhammadiyah semakin mendapatkannya.

Haji Syoedjak yang dipercaya oleh KH. Ahmad Dahlan, pendiri Muhammadiyah sekaligus gurunya, memimpin bagian PKO sejak berdiri pertama pada 1920 berfokus merealisasikan pelayanan-pelayanan sosial dengan membangun poliklinik, weeshuis (rumah yatim) dan armhuis (rumah miskin). Sedangkan untuk sekolah yang menjadi wewenang dari bagian Pengajaran juga terus diperbaiki penyelenggaraannya. Keempat-empatnya dikembangkan dengan mengoptimalkan kedermawanan dari masyarakat Yogyakarta dan anggota Muhammadiyah baik di Yogyakarta maupun di luar Yogyakarta, salah satunya wakaf.

De Indische Courant tertanggal 16 Juni 1926 memberitakan bahwa perwakilan zending, missie dan Muhammadiyah diberi kesempatan untuk berbicara pada saat penyambutan kedatangan J.E. Jasper sebagai residen Yogyakarta yang baru. Dalam kesempatan itu Zending, gerakan perkabaran injil agama Kristiani, menyampaikan permohonan dukungan dalam kerja-kerja pelayanan yang mereka lakukan di Yogyakarta. Begitu juga perwakilan dari Missie (misionaris), gerakan penyebaran agama Katholik, yang berharap ada kerjasama yang terjalin dalam rangka mengembangkan otoritas sipil dan kebahagiaan penduduk Yogyakarta. Sedangkan Muhammadiyah menjabarkan aktivisme pelayanan umum yang telah mereka lakukan selama ini yang mencakup pada empat hal: armenhuis (rumah miskin), poliklinik, weeshuis (rumah yatim) dan schoolen (sekolah). ${ }^{4}$

Paparan historis mengenai aktivisme filantropi di Yogyakarta, khususnya wakaf di Yogyakarta pada 1920-an-1930-an memang belum ada yang secara komprehensif menulis. ${ }^{5}$ Namun tidak halnya dengan kedermawanan secara umum. Abdurrachman Surjomihardjo (2008) dalam Kota Yogyakarta Tempo Doeloe yang menyatakan bahwa pada 1923 Muhammadiyah telah memiliki 
sebuah Kweekschoo/ dan HIS di Notoprajan, sekolah Ongko Loro di Bausasran, Kauman dan Karangkajen dengan total jumlah guru 40 orang dan murid 974 orang. ${ }^{6}$ Berpijak dari data tersebut, penelitian ini memungkinkan untuk mengelaborasi lebih komprehensif hadirnya wakaf sebagai bagian dari aktivisme kedermawanan yang dilakukan oleh Muhammadiyah di dekade kedua abad XX. Lebih spesifik tentang aktivisme filantropi yang dilakukan PKO, berdasarkan catatan Bambang Purwanto bahwa PKO milik Muhammadiyah di Yogyakarta pada pertengahan 1920an yang telah mengelola sebuah rumah miskin, dua panti asuhan dan satu klinik kesehatan juga bisa ditelusur hal yang sama dalam rangka melacak perkembangan kedermawanan Islam di Yogyakarta. $^{7}$

Amelia Fauzia dengan desertasinya "Faith and the State: a History of Islamic Philantrophy in Indonesia", mengisi ruang kajian historis mengenai filantropi Islam di Indonesia. Meksi temporal periodenya sangat panjang dan kajiannya cukup luas yakni mencakup Hindia-Belanda, namun secara spesifik Fauzia juga menyinggung pertumbuhan kegiatan filantropi dan kedermawanan di Yogyakarta, terutama yang dikelola oleh Muhammadiyah. Dalam salah satu bagian desertasinya, Fauzia memaparkan perbandingan filantropi Islam yang dikelola di masa kolonial dengan setelah kemerdekaan. Di masa sebelum kemerdekaan, Fauzia mencoba memetakan bagaimana peran pemerintah kolonial dalam mengatur regulasi kegiatan filantropi dan bagaimana perkembangan institusi yang bersinggungan dengan sedekah dan wakaf yakni masjid dan pesantren. Pembahasan tentang kontestasi Muhammadiyah dan Nahdahatul Ulama dalam mengelola zakat dan fitrah juga disinggung Fauzia. Sedangkan setelah kemerdekaan, pembahasaan Fauzia mencakup perkembangan filantropi Islam selama perang kemerdekaan dan juga bagaimana modernisasi pengelolaan wakaf setelah kemerdekaan. ${ }^{8}$ Dibandingkan dengan disertasi Fauzia, tesis ini masih mempunyai ruang untuk mengembangkan wacana khususnya pada transformasi kedermawanan pada kurun 1920-an-1930-an.

Berbeda dengan apa yang ditulis Fauzia, Hilman Latief yang menulis disertasi Islamic Charities and Social Activism: Welfare, Dakwah and Politics in Indonesia lebih menyajikan secara konseptual bahwa kedermawanan Islam memiliki dimensi kesejahteraan, dakwah dan politik dengan temporal yang lebih kontemporer. Dari sisi kesejahteraan, Latief memaparkan model berkembangnya kedermawanan melalui klinik gratis, rumah sakit, program pelayanan kesehatan dari tiga organisasi kedermawanan Islam yakni Dompet Dhuafa, 
Rumah Zakat Indonesia dan Muhammadiyah. Selain itu, dalam aspek kesejahteraan itu Latief juga mengulas tentang kedermawanan dalam upaya pemberdayakan perempuan dengan salah satu isu perdagangan perempuan. Dari perspektif dakwah, Latief mencoba menganalisis sebuah aktivitas dakwah Islam di lokasi yang muslim menjadi minoritas, yakni Pulau Nias. Terakhir, dalam sisi politik, Latief mencoba memaparkan bahwa dalam banyak kasus kedermawanan juga dibangun atas sentiment politik, sebagai contoh isu pembebasan Palestina, Anti-Yahudi dan Anti-Amerika. ${ }^{9}$

Tulisan yang menggunakan metode sejarah ini ingin melihat sejauh mana gerakan pelayanan sosial yang dilakukan oleh Bagian PKO Hoofdbestuur Muhammadiyah di Yogyakarta pada kurun 1920-1931 dapat membangun posisi tawar masyarakat sipil di mata pemerintah Kolonial Belanda. Di tengah ketimpangan kondisi sosial karena modernisasi perkotaan Yogyakarta di awal abad XX tidak cukup dapat dinikmati oleh seluruh masyarakat, menarik untuk melihat kiprah Bagian PKO Hoofdbestuur Muhammadiyah dalam pengelolaan pelayanan sosial masyarakat. Hal ini juga bisa bisa dilihat sebagai bentuk respons masyarakat sipil atas absennya negara terhadap peningkatan kesejahteraan masyarakat yang lebih luas. Sumber-sumber yang digunakan dalam artikel ini adalah arsip resmi, surat kabar sezaman dan buku-buku sekunder.

\section{PKO sebagai Produk Institusionalisasi Pelayanan Sosial Muhammadiyah}

Hoofdbestuur Muhammadiyah memiliki bagian PKO yang diresmikan dalam Rapat Anggota Istimewa Muhammadiyah pada 18 Juni 1920. ${ }^{10} \mathrm{KH}$ Ahmad Dahlan mempercayakan PKO dipimpin oleh Soedjak. Ketika ditunjuk menjadi Ketua Bagian PKO dan ditanya oleh KH Ahmad Dahlan tentang apa yang akan dilakukannya ketika memimpin bagian ini, Soedjak menjawab, "Hendak membangun hospital untuk menolong kepada umum yang menderita sakit." KH Ahmad Dahlan bertanya lagi, "Dan selain daripada itu hendak membangun apa pula?". Soedjak menjawab, "Hendak membangun Armhuis (rumah miskin)". Kemudian ditanya lagi pertanyaan yang sama, Soedjak menjawab, "Hendak mendirikan weeshuis (rumah yatim)."11

Jawaban Soedjak menuai tertawaan para peserta Rapat Anggota Istimewa yang menyangsikan target-target yang dirancang Soedjak. Menjelang rapat usai pukul 12 malam, Soedjak meminta izin kepada KH Ahmad Dahlan selaku pimpinan rapat untuk berbicara. Soedjak mengatakan:

"Pimpinan Yang Mulia dan Saudara sekalian yang terhormat. Assala- 
mu'alaikum warohmatu Allahi wabarokatuh. Sungguh, sangat menyesal dan keciwa hati saya, ketika saya mendengar sambutan atas jawaban saya terhadap pimpinan sidang dengan gelak ketawa yang mengandung isi seolah-olah melemahkan semangat jiwa saya yang penuh keyakinan atas dasar pengetahuan (ilmu yaqin) daripada ajaran Agama Islam yang sumbernya kitab suci Al-Qur'an dan Sunnah Rasul Muhammad saw.

Dalam Al-Qur'an dapat kita lihat masih tercantum Surat Al-Ma'un dengan ayat dan lengkap tidak sehurufpun yang kurang sekalipun berubah, arti dan maknanya pun tetap sejak turun diwahyukan oleh Allah sampai kini tetap juga.

Meskipun kitab suci Al-Qur'an sudah berabad-abad dan surat Al-Ma'un menjadi bacaan sehari-hari dalam sembahyang oleh umat Islam Indonesia pada umumnya dan di Yogyakarta pada khususnya, namun sampai kini belum ada seorang dari umat Islam yang mengambil perhatian akan intisarinya yang sangat penting itu untuk diamalkan dalam masyarakat. Banyak orang-orang di luar Islam (bukan orang Islam) yang sudah berbuat menyelenggarakan rumah-rumah Panti Asuhan untuk memelihara mereka si fakir miskin dan kanak-kanak Yatim yang terlantar dengan cara sebaikbaiknya hanya karena terdorong dari rasa kemanusiaan saja, tidak kerna merasa bertanggung jawab dalam masyarakat dan tanggung jawab di sisi Allah kelak di hari kemudian.

Kalau mereka dapat berbuat karena berdasarkan kemanusiaan saja, maka saya heran sekali kalau umat Islam tidak dapat berbuat. Padahal agama Islam adalah agama untuk manusia bukan untuk khalayak yang lain. Apakah kita bukan manusia? Kalau mereka dapat berbuat kena apakah kita tidak dapat berbuat? Hum rijalu wa nahnu rijal. (mereka manusia kitapun manusia).

"Saudara-saudara yang terhormat dan yang tertawa, rupanya saudarasaudara itu masih belum yakin percaya kepada Allah swt. dan belum yakin percaya kepada kitab-Nya, sehingga saya bercita-cita akan membangun Hospital, Rumah Miskin dan Rumah Yatim saja, seolah-olah mustahil akan dapat terlaksana, karena Saudara pandang ketiadaan kemampuan kita diwaktu sekarang ini, sehingga cita-cita kita Saudara pandang sangat melampaui batas. Allah Ta'ala tidak memerintahkan kepada kita hambaNya sesuatu yang bukan bakatnya walau pun soal yang sekecil-kecilnya. Tetapi Allah ta'ala memerintahkan kepada kita sesuatu yang kita dapat meleksanakan walaupun soal yang besar dan berat. Saudara-saudara, kita 
telah membangun Persyarikatan Muhammadiyah untuk mentaati perintahperintah Islam yang bersumber kitab Al-Qur'an. Taatilah dengan sungguhsungguh menurut petunjuk dan sunnah Rasullullah serta dengan kepercayaaan yang yakin dan penuh semangat yang giat."12

Haji Soedjak yang bernama kecil Danil/Daniyalin adalah murid generasi pertama KH. Ahmad Dahlan, bersama dua saudaranya Haji Fachrodin (Jazoeli) dan Ki Bagus Hadikusumo (Hidajat). Murid generasi awal yang mendapatkan pendidikan dari KH Ahmad Dahlan lainnya adalah Haji Muhammad Zain, Haji Muhammad Mokhtar, Haji Ahmad Badawi, dan Haji Hajid. Soedjak dilahirkan di Kauman pada 1882. ${ }^{13}$ Ayahnya bernama Hasyim Ismail, seorang Lurah Keraton Yogyakarta. ${ }^{14}$ Sejak kecil dia bersama saudara dan rekan-rekannya berguru kepada KH Ahmad Dahlan. Soedjaklah yang berani bertanya kepada KH Ahmad Dahlan mengapa pada saat itu KH Ahmad Dahlan tidak melanjutkan materi belajarnya. KH Ahmad Dahlan mengulang pembahasan Surat Al-Maun hingga empat bulan. Hingga kemudian dijawab oleh KH Ahmad Dahlan, "Apakah kamu sudah mengamalkannya?"15

Terbentuknya institusi Bagian PKO menjadi tonggak dimulainya kerja-kerja pelayanan Muhammadiyah yang lebih luas. Target pertama yang dibidik oleh PKO adalah pelayanan kesehatan seiring telah berkembangnya pelayanan kesehatan yang diselenggarakan oleh zending yakni Zendinghospitaal Petronella atau yang biasa disebut juga Petronella Hospitaal yang dibangun pada 1899 (sejak 28 Juni 1950 berubah nama menjadi Rumah Sakit Bethesda). Sebuah poliklinik kecil dibuka di Notoprajan pada 1923. Artikel Soerabaijasch Handelsblad tanggal 8 Oktober 1931 melaporkan bahwa klinik rawat jalan tersebut di awal berdirinya dibantu operasionalnya oleh seorang gouvernements-indisch arts (dokter pemerintah) yang bernama Soemowidagdo. Bagian PKO sangat terbantu karena dr. Soemowidagdo bersedia mengabdi di sebuah klinik kecil yang baru didirikan tersebut dan gaji yang harus dia terima sepenuhnya menjadi tanggung jawab pemerintah.

\section{Penggalangan Dana dan Pembiayaaan PKO}

Untuk memenuhi kebutuhan operasional poliklinik, Bagian PKO mengupayakan banyak hal. Sebuah laporan tahunan Klinik dan Poliklinik Moehammadijah bagian PKO yang diterbitkan dalam Soeara Moehammadijah bulan Oktober 1923 terdiri dari pemasukan dan pengeluaran Klinik dan Poliklinik PKO antara 1 Maret 1923 dan 31 Agustus 1923. Laporan ini merupakan 
laporan pertama klinik dan polikiliek setelah didirikan bagian PKO pada bulan Februari. Laporan tersebut menunjukkan bahwa pemasukan PKO didapatkan dari beberapa sumber, antara lain kas Hoofdbestuur Muhammadiyah, penjualan cocard dalam jaarvergadering (pertemuan tahunan) Muhammadiyah, pendapatan peti derma darijaarvergadering, penjualan kok di Comite Voetbal, dan derma dari Comite Voetbal. Pemasukan lain yang didapatkan oleh klinik dan poliklinik yang dikelola bagian PKO adalah dari pendapatan peti derma di poliklinik dan pembajaran klinik dari orang sakit. ${ }^{16}$

\section{Gambar 1.}

Aktivitas PKO yang tergambar dalam perangko di akhir 1930an

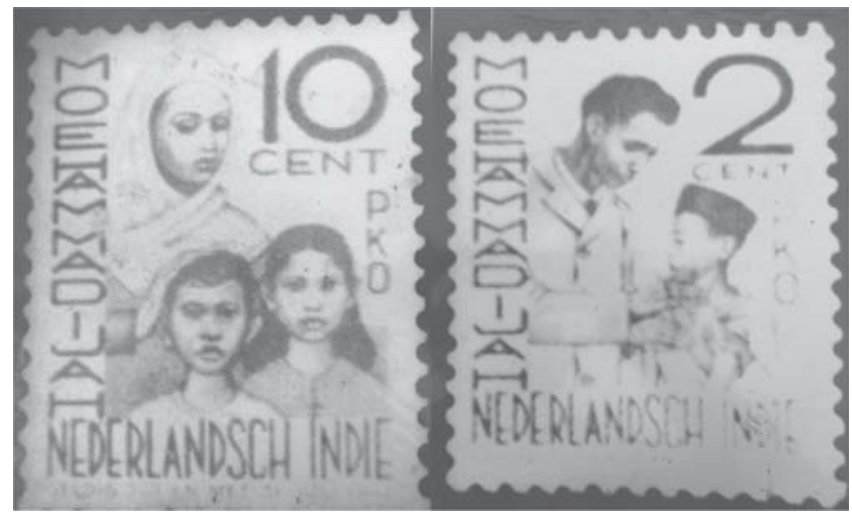

Sumber: Yayasan KH Ahmad Dahlan

Dari laporan setengah tahun klinik dan poliklinik PKO tersebut bisa dipetakan bahwa di setiap awal semester, bagian PKO mendapatkan subsidi dari Hoorfbestuur Muhammadiyah rata-rata f 50 . Sedangkan pemasukan penjualan cocard dan peti derma dari jaarvergadering hanya bisa didapatkan sekali yakni pada paruh semester pertama karena penyelenggaraannya di awal tahun. Untuk derma dari institusi di luar Muhammadiyah seperti dalam hal ini Comite Voetbal tidak pasti didapatkan setiap semesternya.

Sedangkan untuk pengeluaran, jika dilihat dalam laporan, pengeluaran rutin tiap bulan adalah untuk pembelian obat dan penyediaan makan untuk pasien. Selebihnya, mengingat klinik dan poliklinik ini masih baru maka membutuhkan beberapa inventaris antara lain lemari pekakas, sepeda, kasur, bantal, serta piespot. Pembelian cat juga diperlukan dalam merapikan warna dinding agar lebih layak. Pengeluaran lain dalam operasional enam bulan 
klinik dan poliklinik PKO ini adalah untuk membayar poenggawa dokter. ${ }^{17}$ Klinik dan poliklinik PKO tidak perlu membayar gaji dokter karena mendapatkan bantuan tenaga dokter pemerintah gratis yakni dr. Mas Soemowidigdo dan tenaga medis lain yang bernama Mas Slamet. ${ }^{18}$

Tabel 1. Pemasukan dan Pengeluaran Bulanan Klinik da
\begin{tabular}{lll}
\multicolumn{3}{c}{ Moehammadijah bagian PKO } \\
\cline { 2 - 3 } BULAN & PEMASUKAN & PENGELUARAN \\
\hline Maret & $\mathrm{f} 142.20$ & $\mathrm{f} 87.48$ \\
April & $\mathrm{f} 231.915$ & $\mathrm{f} 186.49$ \\
Mei & $\mathrm{f} 5$ & $\mathrm{f} 3.63$ \\
Juni & $\mathrm{f} 10.15$ & $\mathrm{f} 6$ \\
Juli & $\mathrm{f} 26.25$ & $\mathrm{f} 84.27$ \\
Agustus & $\mathrm{f} 234.15$ & $\mathrm{f} 161.61$ \\
TOTAL & $\mathrm{f} 649.665$ & $\mathrm{f} 529.48$ \\
\hline
\end{tabular}

Sumber: Diolah dari Soeara Moehammadijah, Oktober 1923

Tabel 2. Pemasukan peti derma dan pembayaran orang sakit di Klinik dan Poliklinik Moehammadijah bagian PKO

\begin{tabular}{lll}
\hline BULAN & PETI DERMA & $\begin{array}{l}\text { PEMBAYARAN DARI } \\
\text { ORANG SAKIT }\end{array}$ \\
\hline Maret & $f 6.20$ & - \\
April & $f 11.50$ & - \\
Mei & $f 5$ & - \\
Juni & $f 10.15$ & - \\
Juli & $f 7.50$ & $f 7.50$ \\
Agustus & $f 17$ & $f 17.50$ \\
\hline
\end{tabular}

Sumber: Diolah dari Soeara Moehammadijah, Oktober 1923

Terkait dengan pemasukan dari peti derma klinik dan pembayaran orang sakit, jika menilik laporan (dalam tabel 1), jumlah yang didapatkan sebagai pemasukan PKO sangat tidak signifikan jumlahnya. Peti derma selama setengah tahun hanya mendapatkan f 57.35 sedangkan pembayaran dari orang sakit hanya sebesar $\mathrm{f} 25$ (lihat tabel 2). Bisa dipastikan memang klinik dan poliklinik PKO ini tidak menarik biaya dari layanan yang diberikan kepada masyarakat yang berobat dan hanya menyediakan peti derma bagi siapa yang ingin mendermakan harta yang dimilikinya tanpa tarif khusus. Dengan kata lain klinik dan poliklinik PKO di awal berdirinya tidak bertujuan untuk mendapatkan 
keuntungan. Bahkan pada semester berikutnya, kas bagian PKO yang membawahi klinik dan poliklinik semakin defisit dan tidak sehat untuk bisa membiayai kegiatan pelayanan yang lain seperti weeshuis dan armen-huis. ${ }^{19}$

Di tengah kondisi keuangan Moehammadijah Bagian PKO yang sulit, bagian PKO yang dipimpin Soedjak mencoba terus melaksanakan tugas-tugas pelayanan sesuai dengan proporsi yang diberikan oleh hoofdbestuur Muhammadiyah. Dalam rangka tetap menyokong keuangan, bagian PKO terus mengupayakan terkumpulnya derma dari masyarakat maupun anggota Muhammadiyah. Selain itu, bagian PKO juga membuka restaurant di Kampung Kauman pada saat bulan puasa. Dalam terbitan Soeara Moehammadijah, Oktober 1923, Dirjowongso selaku Secretarie bagian PKO meminta para pembaca Soeara Moehammdijah agar tidak belanja di selain restaurant itu karena berapapun keuntungan yang didapatkan akan bisa masuk untuk kas PKO. Namun, Dirjowongso melanjutkan tulisannya "Adapoen kalau restaurant itoe meroegi di pikoel sama rata oleh Bestuur-bestuur semoea". Restaurant yang dibuka oleh Bagian PKO ini hanya dibuka sampai Idul Fitri karena bagian PKO mempunyai tugas untuk menerima zakat fitrah dari masyarakat Yogyakarta. Pengumpulan zakat fitrah inilah yang menjadi cikal bakal pendirian armenhuis (rumah miskin) Muhammadiyah. ${ }^{20}$

PKO mengembangkan model institusionalisasi/pelembagaan kedermawanan melalui pembentukan panitia dalam pengumpulan derma. Sebagaimana dilaporkan De Indische Courant tertanggal 17 November 1927, setelah klinik dan poklinik yang dikelola Hoorfdbestuur Muhammadiyah bagian PKO berdiri, target selanjutnya dari Haji Soedjak selaku penanggungjawab bagian PKO adalah membangun weeshuis. Haji Soedjak menyampaikan rencana Hoofdbestuur Muhammadiyah bagian PKO untuk membangun Inlandsch weeshuis atau rumah yatim untuk bumiputera. Hoofdbestuur Muhammadiyah sudah membentuk kepanitiaan dan memperkirakan biaya pembangunan rumah yatim tersebut diperkirakan sebesar f 15.000. ${ }^{21}$ Pemberitaan di surat kabar baik yang diterbitkan oleh internal Muhammadiyah (Soeara Moehammadijah) ataupun komunitas Islam lainnya (Adil, Bintang Islam, dII) bahkan juga koran kolonial (De Indische Courant, Soerabaijasch Handelsblad, dll) dimaksudkan agar banyak anggota Muhamamdiyah ataupun masyarakat umum lainnya yang tergerak membantu. Akhirnya, setelah selesai dibangun dan diresmikan pada 1931, bangunan weeshuis itu menghabiskan biaya f 47.000 dan jumlah tersebut berhasil dikumpulkan oleh panitia. ${ }^{22}$

Pembentukan panitia dalam menggalang dana untuk pembangunan tidak 
hanya dilakukan oleh Bagian PKO. Hoofdbestuur Muhammadiyah untuk sebuah usaha yang belum dikerjakan secara spesifik oleh bagian tertentu maka akan turut mengumpulkan derma secara langsung. Sebagai contoh pada saat pembangunan langgar khusus perempuan di Kauman, Yogyakarta. Hoofdbestuur Muhammadiyah membentuk panitia dan menyebarkan informasi kepada anggota Muhammadiyah yang ingin berpartisipasi memberikan derma untuk kebutuhan pembangunan. Panitia juga melaporkan semua derma yang diterima dari masyarakat ataupun anggota Muhammadiyah. ${ }^{23}$ Begitu juga ketika Bagian Pengajaran hendak membangun Kweekschool Istri di Notoprajan di atas tanah wakaf Haji Fachrodin. Dana sebesar f 90.000 akhirnya berhasil dikumpulkan oleh panitia dan direalisasikan pembangunan komplek Kweekschool Istri yang terdiri dari masjid, asrama dan perumahan guru. ${ }^{24}$

Jika Hoofdbestuur Muhammadiyah mendapatkan tanah untuk dibangun bangunan tertentu seperti rumah yatim ataupun sekolah maka Hoofdbestuur Muhammadiyah akan mengembangkan tanah dan bangunan wakaf tersebut dimulai sesuai dengan rencana yang telah disusun oleh Hoofdbestuur Muhammadiyah lalu kemudian membentuk kepanitiaan dalam mengumpulkan derma dari masyarakat dan anggota Muhammadiyah.

Pertumbuhan institusionalisasi/pelembagaan kedermawanan (termasuk di dalamnya wakaf) yang dilakukan Muhammadiyah pada 1920an-1930an berkembang signifikan. Di bidang pelayanan kesehatan melalui Klinik dan Poliklinik PKO sebagaimana dilaporkan oleh Soerabaijasch Handelsblad, 8 Oktober 1931 bahwa pada 1929, PKO telah menolong 470 pasien yang dirawat selama 6.357 hari. Pada 1930, jumlah pasien meningkat menjadi 675 pasien yang dirawat selama 7.905 hari. Surat kabar tersebut juga memberitakan pada 1931 jumlah pasien tidak berkurang. Pada 1929, Bagian PKO sudah membuka klinik di Imogiri dan Kotagede, jumlah pasien yang dirawat di masing-masing tempat selama tiga bulan pertama sejak klinik ini dibuka adalah 470 pasien yang dirawat selama 2.805 hari untuk Imogiri dan 367 pasien yang dirawat selama 1.276 hari. $^{25}$

Klinik PKO yang ketika itu dipimpin oleh dr. Sampoerno mempunyai keuangan yang cukup baik. Di tahun 1929 misalnya, PKO menerima subsidi dari pemerintah kolonial sebesar f. 5.400 dan juga dari Keraton Yogyakarta sebesar f. 3.023,53 serta dari pemasukan pasien (biaya perawatan) sebesar $\mathrm{f}$. 2.345. Selain itu PKO pada tahun tersebut juga mendapatkan derma/donasi sebenar f. 500. Jadi, total pendapatan pada tahun 1929 sekitar f 12.000 . Setiap tahunnya klinik dan poliklinik juga merancang rancangan pemasukan 
dan pengularan. Sebagai contoh pada 1930, klinik dan poliklinik PKO memiliki renacana pengeluaran sebesar f. 17.717 dan pendapatan sebesar f. 16.666, sehingga Hoofdbestuur Muhammadiyah Bagian PKO memikirkan bagaimana menutup kekurangan pendanaan tersebut. ${ }^{26}$

Selain mengandalkan subsidi dari pemerintah kolonial (baik untuk operasional klinik/poliklinik, weeshuis dan armen-huis), Muhammadiyah terus menggalang kedermawanan dari anggotanya termasuk di dalamnya wakaf. Akumulasi derma tersebut diinstitusonalisasi oleh Hoofdbestuur maupun bagian-bagian dari Hoofdbestuur Muhammadiyah. Hoofdbestuur Muhammadiyah membangun produktifitas wakaf dan kedermawanan yang telah diterima sebelumnya. Artinya, ada upaya mengakumulasi modal dari wakaf untuk kelangsungan wakaf itu sendiri untuk tujuan pengembangan kerja-kerja sosial yang telah ada, baik dari iuran "peti derma" di PKO ataupun "iuran sekolah" di sekolah-sekolah, meski jumlahnya tidka signifikan dan hanya digunakan untuk operasional.

Di bidang pendidikan, saat Congres Muhammadiyah 1926 di Surabaya dilaporkan bahwa Muhammadiyah telah memiliki 16 HIS, 1 schakelschool, 40 dessaschool, 15 jatimschoolen, dan 2 kweekschoolen. ${ }^{27}$ Selain itu, setahun sebelumnya, Muhammadiyah tercatat telah memiliki 55 sekolah dengan 4000 murid. ${ }^{28}$ Dalam pelayanan perpustakaan, Muhammadiyah telah memiliki empat perpustakaan di Yogyakarta, Batavia, Surabaya dan Pekalongan dengan koleksi lebih dari 10.000 buku-buku Islam berbahasa Melayu. ${ }^{29}$ Pelembagaan kerjakerja sosial dan kedermawanan yang dilakukan Muhammadiyah membuat Muhammadiyah disebut dalam De Indische Courant sebagai "Orthodixe Mohammedanen" (Islam orthodoks). ${ }^{30}$

\section{PKO dan Posisi Tawar Muhammadiyah sebagai Masyarakat Sipil}

Dua hal yang tampak dari relasi Hoofdbestuur Muhammadiyah dengan pemerintah kolonial Belanda terkait operasional klinik dan poliklinik PKO Muhammadiyah adalah diperbantukannya dokter pemerintah kolonial di klinik tersebut dan diberikannya subsidi untuk operasional pelayanan kesehatan di klinik dan poliklinik tersebut. Diperbantukannya seorang dokter pemerintah dan diberikannya subsidi untuk operasional pelayanan klinik dan poliklinik PKO bermakna bahwa Hoofdbestuur Muhammadiyah memiliki hubungan baik dengan pemerintah kolonial. Hal tersebut menunjukkan meskipun Muhammadiyah hanya merupakan perkumpulan masyarakat bumiputera 
namun memiliki positioning yang cukup diperhitungkan oleh Pemerintah Kolonial Belanda, terlebih ketika mulai mencoba melakukan aktivitas-aktivitas pelayanan layaknya yang sudah dilakukan zending ataupun missie.

Secara tidak langsung, Muhammadiyah yang bercita-cita menyabarkan ajaran Kanjeng Nabi Muhammad untuk pendoedoek bumiputera dan sejak 1923 telah memerankan peran-peran non-state actor. Zending ataupun Missie sebenarnya juga memerankan hal yang sama, namun kesamaan strata sosial (dikarenakan mereka adalah juga orang Eropa) dengan Pemerintah Kolonial, menjadikan Muhammadiyah lebih punya posisi tawar yang lebih tinggi. Artinya, jika Zending dan Missie yang notabene sama-sama orang Eropa dengan pemerintah kolonial menyelenggarakan aktivitas pelayanan maka tidaklah cukup menarik perhatian bagi pemerintah kolonial dibandingkan jika Muhammadiyah yang merupakan organisasi bumiputera yang menyelenggarakan pelayanan sosial.

Faktor lain yang bisa digunakan untuk melihat positioning Muhammadiyah ketika itu adalah sebagaimana diketahui Zending sudah mengembangkan sekolah dan rumah sakit Petronella sejak dekade kedua abad ke XX, sedangkan Missie ketika itu baru mempunyai sekolah dan belum mempunyai tempattempat penyantunan kesehatan. Dalam momentum seperti itu, Hoofdbestuur Muhammadiyah melalui bagian PKO yang hanya merupakan organisasi bumiputera hadir dengan pelayanan kesehatan (klinik) pada 1923 yang disusul dengan pembangunan rumah miskin (armen-huis) beberapa saat kemudian dan juga rumah yatim (weeshuis) pada 1931. Aktivitas pelayanan inilah yang mendapatkan perhatian dari pemerintah kolonial Belanda yang kemudian memberikan dukungan dalam subsidi yang diberikan untuk Muhammadiyah.

Peran-peran yang dilakukan Muhammadiyah melalui bagian PKO di luar struktur birokrasi pemerintah kolonial ketika itu menunjukkan bahwa kekuatan masyarakat sipil dalam masyarakat Hindia Belanda cukup berkembang. Upaya membiayai sendiri aktivitas sosial dengan melembagakan kedermawanan dari masyarakat dan anggotanya tanpa menggantungkan bantuan dari pemerintah kolonial Belanda, meski kemudian juga mendapatkan subsidi, menunjukkan bahwa masyarakat bumiputera yang notabene menempati strata sosial terendah memang cukup berdaya sebagai kekuatan sipil di luar pemerintah.

Sudut pandang lain yang bisa digunakan untuk melihat hal ini bahwa sangat mungkin pilihan politik Muhammadiyah yang kooperatif juga semakin meyakinkan Pemerintah Kolonial Belanda bahwa Muhammadiyah tidak perlu dicurigai dan justru perlu dibantu dengan subsidi. Hal itu sesuai dengan konsep 
politik Islam yang diwariskan oleh Snouck Hugronje, jika ummat Islam melakukan kegiatna sosial, maka kewajiban pemerintah kolonial adalah mendukung. Hal ini juga mulai merubah wajah politik kolonial di abad XIX yang sangat Islamphobia dan hadir dengan segala kecurigaan atas Islam. ${ }^{31}$ Bisa dikatakan juga bahwa Pemerintah Kolonial Belanda benar-benar mempertimbangkan hadirnya Islam sebagai kekuatan sosial yang semakin kuat pada kurun tersebut.

Secara umum, intervensi Pemerintah Kolonial Belanda dalam urusan keagamaan khususnya bumiputera Muslim memang sangat dihindari. Hal ini menjadi salah satu inti nasihat Snouck Hurgronje, pimpinan pertama Kantor Adviseur voor Arab en Inlandsche Zaken sekaligus misionaris dan antropolog yang menulis desertasi Het Mekkaansche feest di Universitas Leiden pada 1880, yang menjadi pertimbangan utama Kantor Adviseur voor Arab en Inlandsche Zaken. Terkait hal itu, ada yang menarik dari pembahasan anggaran biaya Pemerintah Kolonial oleh Volksraad (Dewan Rakyat) tahun 1924 sebagaimana diberitakan oleh De Indische Courant, 5 Juni 1923. Dalam pembukaan rapat Volskraad tersebut beberapa pidato menyoroti masalah terbatasnya anggaran yang dimiliki pemerintah dan banyaknya biaya pembangunan fasilitas umum yang akan dilaksanakan pada tahun mendatang. Maka tidak ada opsi lain bagi pemerintah selain memotong banyak anggaran yang sudah direncanakan. Oleh karenanya, dalam rapat Volksraad itu juga diwacanakan peningkatan pajak kepada masyarakat dan menyoroti bahwa masyarakat lebih tunduk pada perintah agama untuk berzakat daripada membayar pajak. ${ }^{32}$

Sorotan akan zakat muncul karena sebagian anggota Volksraad melihat Islam punya sistem yang memaksa dalam mengumpulan zakat. Namun pendapat itu juga mendapatkan respon dari peserta yang lain yang mengatakan sebenarnya itu bagian dari mekanisme orang-orang Islam untuk mengurangi kemiskinan dan secara tidak langsung juga membantu pemerintah Kolonial Belanda dalam tugas menyejahterakan masyarakat bumiputera yang mayoritas muslim. Menurutnya zakat tak lebih dari pajak 2,5 persen dari harta sesuai yang dimiliki masyarakat (vermogen), 5-10 persen untuk zakat pendapatan/ harta benda (bezitsinkomsten) serta 20 persen dari hasil bumi (mijnbouwinkomsten). ${ }^{33}$

Dalam pertemuan Volksraad tersebut muncul kecemasan bahwa ikatan ketaatan kepada agama Islam dengan membayar zakat akan memunculkan gerakan-gerakan perlawanan (jihad) seperti yang pernah terjadi di akhir abad 
XIX dan awal abad XX di Hindia Belanda. Namun ada pendapat lain yang mengatakan menghubungkan zakat dengan jihad yang menjadi ketakutan Pemerintah Hindia-Belanda dianggap terlalu berlebihan. Ketakutan Pemerintah Belanda hadir seiring dengan asumsi mereka tentang dijadikannya zakat sebagai modal sosial untuk memberontak seperti yang terjadi pada Perang Jawa dan Padri. Satu hal yang seharusnya dilakukan pemerintah yakni cukup melakukan pengawasan saja. ${ }^{34}$

\section{Bentuk Pelayanan PKO di Awal Berdiri35}

\section{POLIKLINIK KESEHATAN}

Mendirikan hospital adalah mimpi besar Sudjak ketika ditanya KH Ahmad Dahlan tentang apa yang ingin dilakukan ketika memimpin bagian PKO di depan peserta rapat anggota istimewa Muhammadiyah pada 18 Juni 1920. ${ }^{36}$ Syoedjak bersama anggota bagian PKO mencoba merealisasikan target besarnya itu dengan membuka klinik sederhana pada 15 Februari 1923 di kampung Jagang Notoprajan Yogyakarta. Klinik ini dinamakan Penolong Kesengsaraan Oemoem, sama dengan nama bagian yang dipimpinnya. ${ }^{37}$ Meskipun belum membangun hospital, namun klinik ini merupakan penunaian komitmen Syoedjak dan bagian PKO yang dipimpinnya untuk menolong masyarakat umum yang sakit.

Gambar 2. Suasana Kliniek dan Polikliniek Muhammadiyah di Notoprajan, 1924

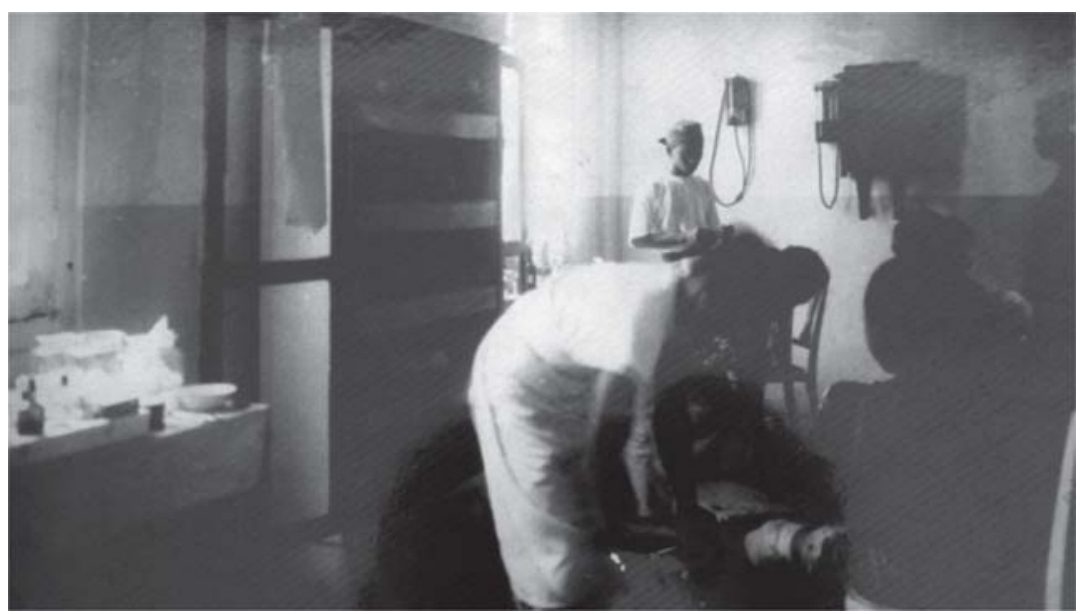


Dari sebuah foto bertahun 1924, poliklinik Muhammadiyah bagian PKO tersebut tampak sederhana. Klinik tersebut hanya terdiri dari satu ruangan yang tidak terlalu luas. Di sudut ruangan terdapat lemari dan meja tempat meletakkan obat. Tampak poenggawa dokter yang sedang memeriksa pasien. Di sudut ruangan lain terdapat meja kursi dan alat-alat medis yang sangat sederhana. Inilah gambaran awal klinik dan poliklinik Muhammadiyah bagian PKO di Jagang Notoprajan, sebelah barat Kauman Yogyakarta. ${ }^{38}$

Pada perkembangannya, kebutuhan tempat yang semakin mendesak membuat Bagian PKO memindahkan ke tempat yang lebih memadai. Jika sebelumnya menggunakan rumah keluarga Syoedjak sehingga tidak perlu menyewa, pada 1928 Bagian PKO menyewa rumah di Ngabean Straat 12 B sebagai tempat baru klinik dan poliklinik ini. Pemindahan ini tidak terlepas dari kedatangan dr. Soekiman, aktivis Partai Serikat Islam, yang menawarkan kerjasama pengelolaan klinik dan poliklinik bersama. Namun dikarenakan menemukan banyak ketidakcocokan, akhirnya PSI dan Hoofdbestuur Muhammadiyah menghentikan kerjasamanya dan Klinik PKO dipindahkan lagi. ${ }^{39}$ Delapan tahun kemudian, pada 1936 klinik dan poliklinik ini berpindah dengan menempati tanah milik Sultan di sebelah timurnya Ngabeanstraat 20.40

Di bidang kesehatan. zending telah memiliki rumah sakit sejak 20 Mei 1899. Rumah sakit tersebut bernama Petronella yang memiliki misi tidak memandang apa dan siapa yang sakit tetapi harus ditolong terlebih dahulu. ${ }^{41}$ Artikel dalam Het Nieuws van den Dag voor Nederlandsch-Indie tertanggal 11 Februari 1922 memberitakan bahwa Petronella-hospitaal mengadakan pengobatan gratis untuk 2000 orang. ${ }^{42}$ Baru pada 14 September 1929, missie membuka Onder de Bogen hospitaal atas prakasa Ir. Schmutzer, direktur pabrik gula di Ganjuran setelah membangun kurang lebih satu tahun. Sembari menunggu proses pembangunan, lima suster St. Gaudentia Brand, St. Yudith de Laat, St. Ignatia Lammens, Sr. Simonia, Sr. Ludolpha de Groot pada Januari 1929 didatangkan sebagai bagian dari gerakan missie untuk bergerak memberikan layanan kesehatan bagi masyarakat Yogyakarta. ${ }^{43}$

Selain Muhammadiyah, zending dan missie, sebagaimana diberitakan oleh Soerabaijasch Handelsblad, 8 Januari 1930, masyarakat Tionghoa di Yogyakarta juga memiliki Chineesche Poliklinik yang terletak di belakang Pemukiman orang-orang Tionghoa Yogyakarta "Hwa Kiauw". Poliklinik ini dipimpin oleh Tan Sien Tjoan. Ada tiga dokter yang akan membantu melayani pasien di sana, yakni dr. Polak, dr. Sie Boen Lian dan dr. Sampoerno yang tak lain adalah dokter sekaligus pimpinan Poliklinik PKO milik Hoofdbestuur Muhammadiyah. ${ }^{44}$ 


\section{WEESHUIS (RUMAH YATIM)}

Setelah klinik dan poklinik yang dikelola Hoorfdbestuur Muhammadiyah bagian PKO berdiri, target selanjutnya dari Haji Syoedjak selaku penanggungjawab bagian PKO adalah membangun weeshuis. De Indische Courant tertanggal 17 November 1927 memberitakan bahwa salah satu pengurus Muhammadiyah, Haji Syoedjak menyampaikan rencana Hoofdbestuur Muhammadiyah bagian PKO untuk membangun Inlandsch weeshuis atau rumah yatim untuk bumiputera. Hoofdbestuur Muhammadiyah sudah membentuk kepanitiaan dan memperkirakan biaya pembangunan rumah yatim tersebut diperkirakan sebesar f 15.000.45

Pembanguan weeshuis Muhammadiyah dilakukan bertahap. Meski bangunan belum sepenuhnya jadi, pelayanan kepada anak yatim sudah diberikan. Hingga pada 5 Oktober 1931 diselenggarakan peresmian Weeshuis Muhammadiyah yang terletak di Kampung Lowanu, Toengkak. Peresmian itu dihadiri oleh Gouverneur van Djokja, Sultan Hamengkubuwana VIII, Pangeran Ario Adipati Pakualaman, Resident van Djokja, pejabat dari Binnenland Bestuur, para pangeran dan penguasa kerajaan lainnya serta undangan dari berbagai kalangan masyrakat bumiputera. ${ }^{46}$

\section{Gambar 3. Masjid di Komplek Weeahuis Muhammadiyah,} Toengkak, 1930an

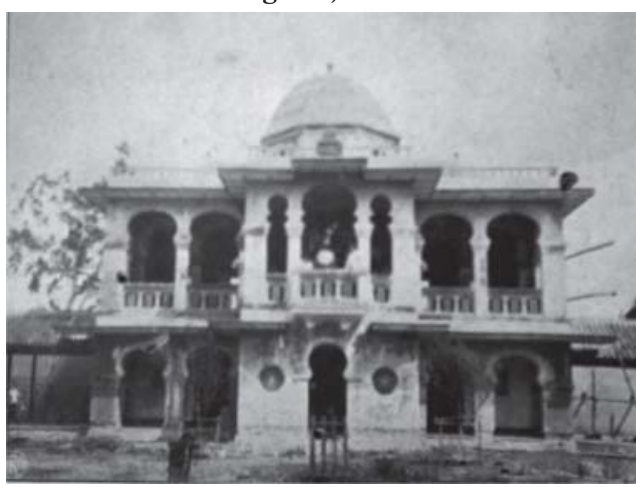

Sumber: Masdjid dan Makam Doenia Islam, tt, h. 28

Dalam peresmian itu, setelah Haji Syoedjak dan Gouverneur van Djokja berbicara, diadakan peninjauan ke dalam kompleks Weeshuis Muhammadiyah yang dipandu oleh Haji Ibrahim. salah satu Hoofdbestuur Muhammadiyah, Kompleks ini terdiri dari dua sayap dan kantor direktur dengan teras belakang 
yang terbuka di tengah. Keduanya di hubungkan dengan taman. Di bagian depan sayap terdapat reseptionis dan rumah instruktur dan guru. Setelah ruang sekolah dan ruang makan, terdapat kamar-kamar siswa. Di bagian belakang komplek tersebut terdapat gudang, dapur serta kamar perawatan bagi yang sakit. Di antara dua baris kamar terdapat taman bermain. Kedua baris kamar tersebut terhubung dengan kamar mandi. ${ }^{47}$

Di bagian belakang komplek tersebut dibangun Masjid dengan arsitektur gaya Turki Chen. Desain masjid tersebut agak tinggi sehingga untuk mencapainya harus menaiki tangga. Di bagian selatan dari kompleks weeshuis ini ada lahan tanah yang disediakan bagi para siswa binaan yang ingin mengembangkan pengetahuan tentang tanaman holtikultura. Hasil panen tanaman-tanaman itu bisa dimanfaatkan untuk kebutuhan dapur mereka. Komplek weeshuis Muhammadiyah ini didesain oleh Ir. Baumgarten dan diawasi oleh Ir. Soeradin. Biaya yang dibutuhkan dalam pembangunan komplek ini mencapai f 43.000 .48

Weeshuis ini mampu menampung hingga 75 anak namun karena peraturan dari Directeur van Justitie membatasi jumlah maksimal hanya 50 anak, maka tidak diisi dengan jumlah yang maksimal. Anak-anak yang ditampung di weeshuis ini merupakan anak yatim piatu atau yatim yang berusia antara 510 tahun. Namun ada juga gelandangan yang ditakutkan menjadi beban masyarakat yang ditampung di weeshuis ini. Anak-anak tersebut selain menadapatkan pendidikan juga mendapatkan ketrampilan di bidang kerajinan. ${ }^{49}$

Dalam menjalankan operasional weeshuis, Hoofdbestuur Muhammadiyah menjaring kedermawanan dari masyarakat Yogyakarta dan anggota Muhammadiyah. Selain mengandalkan sokongan dan derma dari internal, Hoofdbestuur Muhammadiyah Bagian PKO mendapat bantuan dari pemerintah kolonial dan Sultan Hamengkubuwana VIII. Pemerintah kolonial, Keraton Yogyakarta dan Kadipaten Pakualaman memberikan subsidi bulanan untuk operasional weeshuis Muhamamdiyah tersebut.

Berdasarkan gouvernementsbes/uit yang diterbitkan oleh Directeur van Justitie, weeshuis Muhammadiyah akan mendapatkan subsidi dari pemerintah f 3.000 setiap tahun, dengan rincian $\mathrm{f} 5$ untuk setiap anak yang diberikan setiap bulan. Subsidi tersebut akan diserahkan kepada bagian PKO pada setiap akhir tahun. Selain itu, Directeur van Justitie juga membuat peraturan pembatasan jumlah anak yang ditampung di weeshuis tersebut tidak lebih dari 50 anak. Setiap tahunnya, bagian PKO juga harus melaporkan penggunaan 
uangnya dalam laporan akuntansi yang telah ditentukan oleh Directeur van Justitie. ${ }^{50}$ Selain itu, Keraton Yogyakarta juga memberikan subsidi f 1.8 perbulan untuk setiap anak. ${ }^{51}$

\section{ARMEN-HUIS (RUMAH MISKIN)}

Program penyantunan untuk orang-orang miskin melalui pengumpulan zakat fitrah telah dilakukan oleh Hoofdbestuur Muhammadiyah sebelum terbentuknya Bagian PKO pada 1920. ${ }^{52}$ Bagian PKO membuka penerimaan zakat fitrah pada malam hari raya Idul Fitri mulai pukul 7 petang hingga pukul 12 malam. Lebih dari seribu orang menyerahkan zakat fitrahnya melalui PKO. Banyaknya beras yang terkumpul pada Ramadhan tahun 1923 ini membuat bestuur-bestuur bagian PKO harus mendistribusikan fitrah dari pukul 6 pagi hingga siang hari. Pada pukul 11, ribuan orang miskin telah berkumpul di Masjid Gedhe untuk menerima pembagian zakat fitrah tersebut. Mereka membawa karcis yang telah dibagikan oleh bestuur-bestuur bagian PKO tiga hari yang lalu.

Setiap masyarakat penerima fitrah akan mendapatkan 3 kati (1 kati=6,25 ons) dan ternyata jumlah beras yang terkumpul tidak mencukupi jika dibagikan kepada seluruh masyarakat. Akhirnya, bagian PKO mengumpukan uang untuk membeli 1 pikoel (sama dengan sekitar 60 kg, ukuran berat maksimal yang bisa diangkat manusia) beras lagi untuk menambah kekurangan tersebut. ${ }^{53}$ Dirjowongso memberi gambaran kondisi orang-orang miskin di Yogyakarta dalam tulisannya:

"pada hari itoelah hati kaoem miskin terasa betoel atas nasibnja. Sebab melihat beberaa manoesia jang sepadan djoega dengan dirinja sama klihatan makan enak, dengan berpakaian serba bagoes, dan meliat djoega beberapa manoesia sama bersalaman dengan temannja, tapi si miskin pada hari itoe kebetulan minta bekal hidoepnja kepada PKO, dengan berpakaian serba sobek, dan klihatan sama koeroes-koeroes jang menambah kejakinan kita, kalau di dalam kesehari-harinja merika koerang tentang makannja. Dan waktoe itoe kita wadjib merasakan betoel tentang kewadjiban kita kaoem Islam, sebagi jang telah difirmankan Toehan, terseboet dalam soerat Ma'oen.

Seoedahnja kita ingat pada kewadjiban kita itoe, hendaklah teroes di djalankan, sekedar kekoewatan kita, boeat menolong orang miskin itoe. Djalan boeat menjoekoepkan pertolongan kita terhadap pada fakir dan miskin itoe, jang lebih moedah, hendaklah di masing-masing perdijaman 
toean soepaja didirkan perkoempoelan jang semata-mata sengadja menolong pada kesengsaraan oemoem, dengan menoeroet firman-firman Toehan. Sebab dengan djalan perkoempoelan ini, kita dapat mentjoekoepkan perintah-perintah Toehan; Jang kekoeatannja hanya sedikit dengan djalan ini djoega dapat menjoekoepi perintah Toehan itoe lebih-lebih kaoem jang hartawan.

Sesoenggoehnja walau ta' dengan djalan koempoelan bisa djoega kita menolong pada si miskin itoe, oempanaja, dengan djalan kalau ada orang datang di roemah kita (sebagai kebiasaan sekarang ini) bermaksoed mintaminta di sitoe laloe kita kasi wang 1 atau 2 cent." ${ }^{54}$

Jika tulisan Dirjowongso di atas diperhatikan, ia mengatasnamakan secreatarie PKO mencoba memberikan penerangan agama tentang pentingnya berderma kepada orang miskin. Perlunya meningkatkan kepedulian kepada orang-orang miskin karena memang perintah agama yang tertuang dalam surat al-Maun. la juga menyarankan agar lebih banyak lagi perkumpulan yang mmebuat program-program penyantunan untuk orang miskin. Ataupun setidaknya jika ada orang yang datang meminta-minta ke rumah diberi uang 1 atau 2 sen. Namun, meski menyarankan untuk memberi ketika ada pemintaminta datang ke rumah, Dirjowongso juga menulis harapannya jangan sampai orang-orang miskin itu selamanya hidup dengan meminta-minta saja. Seharusnya yang kemudian harus dipikirkan, lanjut Dirjowongso, adalah upaya untuk mendidik mereka agar gemar bekerja, kecuali jika ada bagian tubuhnya yang cacat. ${ }^{55}$

Gambar 4. Altivitas Pembagian Zakat oleh Hoofdbestuur Muhammadiyah Bagian PKO kepada Warga Miskin

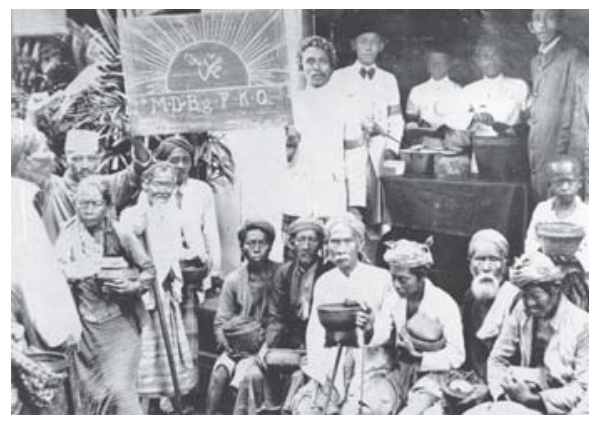

Sumber: Yayasan KH. Ahmad Dahlan 
Masih dalam catatannya, Dirjowongso mengatakan bahwa sesungguhnya pada diri orang miskin itu terkadang juga rusak kemanoesiaan dan igamanja. Dua hal itu harus diperbaiki agar mereka bisa hidup setara dengan manusia yang lainnya. Dirjowongso memberikan solusi, "Bagaimana djalannja akan memperbaiki itoe hal? O! ta'lain toean-toean, hanja dengan djalan ktia haroes mengadakan roemah pemeliharaan orang-orang miskin. ". ${ }^{56}$

Dirjowongso mencoba menawarkan konsep rumah miskin yang dimaksudnya tersebut. Menurutnya, jika kaum Muslim di Hindia-Belanda ini mengeluarkan uangnya tiap bulan f 0,10 saja, dan di Hindia-Belanda ini terdapat 1 juta orang, maka setiap bulan kita bisa mengumpulkan uang sebanyak $f$ 100.000 dan dalam satu tahun sebesar f 1.200.000. Jika nominal tersebut dibuatkan rumah miskin dengan anggaran f 10.000 saja, maka kita bisa membuat 120 rumah. Dirjowongso menambahkan, jika rumah-rumah tersebut disebar masing-masing afdeeling satu rumah miskin maka akan ada 120 afdeeling yang memiliki rumah miskin. Jika masing-masing rumah bisa menampung 100 orang maka yang tertolong dari program rumah miskin ini sudah 12.000 orang. Drijowongso menutup tulisannya, jika program ini dapat berjalan selama 10 tahun, maka dia yakin hampir semua distrik telah berdiri rumah miskin tersebut. ${ }^{57}$

Muhammadiyah akhirnya merealisasikan berdirinya armen-huis sebagaimana yang dibayangkan oleh Drijowongso dalam artikelnya di Soeara Moehammadijah, Oktober 1923 di Serangan, tepi Sungai Winongo. ${ }^{58}$ Namun tidak ada data yang cukup menjelaskan kapan Muhammadiyah merealisasikan pembangunan "armen-huis" tersebut. Dalam menyokong operasional "armenhuis" tersebut, Hoofdbestuur Muhammadiyah bagian PKO mengumpulkan derma dari masyarakat dan anggota Muhammadiyah serta mendapatkan subsidi dari pemerintah kolonial dan kraton. Artikel Bataviaasch Nieuwsblaad tertanggal 11 Februari 1925 memberitakan bahwa gerakan penyantunan orang-orang miskin yang dikelola oleh Hoofdbestuur Muhammadiyah bagian PKO ini juga pernah mendapatkan subsidi dari Kasultanan Yogyakarta sebesar f 1.200 dan f 300 dari Kadipaten Pakualaman. ${ }^{59}$

\section{Kesimpulan}

Karakter pelayanan sosial yang dikembangkan oleh Muhammadiyah melalui Bagian PKO pada kurun 1920 hingga 1931 memang masih terkesan bersifat reaktif. Muhammadiyah tergerak untuk giat melakukan banyak kegiatan pelayanan sosial yang dikembangkan dari kedermawanan dalam rangka 
merespon aktivitas Zending dan kemudian disusul Missie di Yogyakarta yang terus bergeliat. Namun meskipun begitu yang tidak dapat dipungkiri adalah Bagian PKO telah melakukan sesuatu yang belum pernah dilakukan oleh masyarakat bumiputera di Yogyakarta sebelumnya. Didirikannya poliklinik, rumah miskin dan rumah yatim milik Muhammadiyah menunjukkan posisi tawar Muhammadiyah di mata Pemerintah Kolonial Belanda dan juga pemerintah tradisinal: Kasultanan Yogyakarta dan Kadipaten Pakualaman. Muhammadiyah sebagai aktor di luar negara sekaligus masyarakat sipil telah melakukan sesuatu dalam rangka meningkatkan kesejahteraan sosial masyarakat di saat negara belum bisa memberikan hal tersebut dikarenakan diskriminasi kelas yang masih terjadi di banyak wilayah Hindia Belanda, termasuk Yogyakarta.

\section{Catatan Akhir}

1 Abdurrachman Surjomiharjo, Kota Yogyakarta Tempo Doeloe, (Jakarta: Komunitas Bambu, 2008), h. 144.

2 Ibid., h. 145.

3 Muhammad Syoedja', Cerita tentang Kiyai Haji Ahmad Dahlan: Catatan Haji Muhammad Syoedja', tidak diterbitkan, h. 97.

4 De Indische Courant, 16 Juni 1926.

5 Farid Wadji dan Mursyid pernah menulis dalam Bab III bukunya tentang perkembangan regulasi wakaf di Indonesia. Dia menulis regulasi wakaf di zaman Hindia-Belanda. Selain sumber Bijblad tahun 1905 No. 6196, Bijblad tahun 1931 No. 1253, Bijblad tahun 1934 No. 13390, dan Bijblad tahun 1935 No. 13480, sumber lain untuk menyatakan wakaf sudah mulai ada sejak abad XVI menurut saya meragukan. Lihat: Farid Wadjdy dan Mursyid, Wakaf dan Kesejahteraan Ummat Filantropi Islam yang Hampir Terlupakan, (Yogyakarta: Pustaka Pelajar, 2007), h. 38-43.

6 Abdurrachman Surjomihardjo, op.cit., h. 75.

7 Bambang Purwanto, "Capitalizing Charity in Indonesian Muslim Community: The History of PKU Muhammadiyah-Aisyiah Hospital", International conference on "Indigenous Charities: Historical Studies of Institutions Across Culture", Hongkong 6-7 November 2008.

8 Amelia Fauzia, "Faith and the State: a History of Islamic Philantrophy in Indonesia”. Dissertation, (Netherland: Brill's Southeast Asian Library, 2013).

9 Hilman Latief, "Islamic Charities and Social Activism: Welfare, Dakwah and Politics in Indonesia", Dissertation. (Netherland: Leiden Universiteit, 2012). Lihat juga Hilman Latief, Melayani Umat: Filantropi Islam dan Ideologi Kesejahteraan Kaum Modernis (Jakarta: Gramedia, 2010)

10 Muhammad Syoedja', op.cit., h. 97.

11 Ibid., h. 101.

12 Ibid., h. 102-104. 

Fachrodin, Hadikoesoemo, Zaini Sulthoni, Moendjijah, Barijah, dan Walidah. Kedelapannya menjadi pendukung Muhammadiyah. Lihat: Mua'rif, "Tujuh Tokoh Pendiri Muhammadiyah”, dalam Basis, No. 01-02, Tahun Ke-59, 2011, h. 51-52.

15 Diskusi dengan Budi Setiawan (59) di Wirobrajan, 24 Januari 2015.

16 Soeara Moehammadijah, Oktober 1923.

17 Soeara Moehammadijah, Oktober 1923.

18 Bataviaasch Niewsblad, 11 Februari 1925.

19 Soeara Moehammadijah, Desember 1923.

20 Soeara Moehammadijah, Oktober 1923.

21 De Indische Courant, 17 November 1927.

22 Het nieuws van den dag voor Nederlandsch-Indie, 7 Oktober 1931

23 Swara Moehammadijah, Oktober 1923.

24 Muarif, Modernisasi Pendidikan Islam: Sejarah dan Perkembangan Kweekschool Moehammadijah 1923-1932, (Yogyakarta: Suara Muhammadiyah, 2012), h. 136.

25 Soerabaijasch Handelsblad, 8 Oktober 1931.

26 Soerabaijasch Handelsblad, 8 Oktober 1931.

27 De Indische Courant, 24 April 1935.

28 MC Ricklefs, Sejarah Indonesia Modern 1200-2004, (Jakarta: Serambi, 2005), hlm 356.

29 Het Vaderland: Staat-en Letterkundig Nieuwsblad, 31 Maret 1926.

30 De Indische Courant, 24 April 1935.

31 Sartono Kartodirjo, Pengantar Sejarah Indonesia Baru: Sejarah Pergerakan Nasional, (Yogyakarta: Ombak, 2014), h.138.

32 De Indische Courant, 5 Juni 1923.

33 De Indische Courant, 5 Juni 1923.

34 De Indische Courant, 5 Juni 1923.

35 Subchapter ini pernah ditulis dalam versi bahasa Inggris dan dipresentasikan oleh penulis dalam $3^{\text {rd }}$ ASEAN International Conference on Islamic Finance di Semarang, 18-19 November 2015 dengan judul Transformation of Charities by Islamic Social Movements In Yogyakarta, 1912-1931: A History of Islamic Wealth Management.

36 Muhammad Syoedja', op.cit., h. 97.

37 Soerabaijasch Handelsblad, 8 Oktober 1931 dan "Sejarah", dalam www.rspkujogja.com, diakses 19 Januari 2015, 12.36.

38 Arsip Yayasan KH Ahmad Dahlan.

39 Soerabaijasch Handelsblad, 8 Oktober 1931.

40 "Sejarah", dalam www.rspkujogja.com, diakses 19 Januari 2015, 12.36.

41 "Sejarah", dalam www.bethesda.or.id, diakses pada 20 Januari 2015, 19.30.

42 Het Nieuws van den Dag voor Nederlandsch-Indie, 11 Februari 1922.

43 "Jati diri dan Sejarah", dalam www.pantirapih.or.id, diakses 20 Januari 2015, 
19.15.

44 Soerabaijasch Handelsblad, 8 Januari 1930.

45 De Indische Courant, 17 November 1927.

46 Het Nieuws van de Dag voor Nederlandesch-Indie, 7 Oktober 1931.

47 Het Nieuws van de Dag voor Nederlandesch-Indie, 7 Oktober 1931.

48 Het Nieuws van de Dag voor Nederlandesch-Indie, 7 Oktober 1931.

49 Het Nieuws van de Dag voor Nederlandesch-Indie, 7 Oktober 1931.

50 Soerabaijasch Handelsblad, 26 Juni 1929.

51 Het Nieuws van de Dag voor Nederlandesch-Indie, 7 Oktober 1931.

52 Dalam laman muhammadiyah.org, terdapat kronik sejarah yang menjelaskan bahwa Muhammadiyah mulai bergerak dalam pengumpulan dan pendistribusian zakat fitrah sejak 1914. Tahun tersebut adalah tahun pergantian Hoofd Penghulu dari Kiai Muhammad Khalil Kamaludiningrat ke Kiai Mohammad Kamaludiningrat yang simpati kepada Muhammadiyah. Lihat: www.muhammadiyah.org.

53 Soeara Moehammadijah, Oktober 1923, h. 232.

54 Soeara Moehammadijah, Oktober 1923, h. 233.

55 Soeara Moehammadijah, Oktober 1923, h. 233.

56 Soeara Moehammadijah, Oktober 1923, h. 233.

57 Soeara Moehammadijah, Oktober 1923, h. 233.

58 Wawancara dengan Abunda Faruq (74) di Kauman, 6 Februari 2015.

59 Bataviaasch Nieuwsblaad, 11 Februari 1925.

\section{Daftar Pustaka}

\section{Arsip}

Arsip Yayasan KH Ahmad Dahlan

Bijblad 1905 No. 6196

Bijblad 1931 No. 1253

Bijblad 1934 No. 13390

Bijblad 1935 No. 13480

Bataviaasch Nieuwsblaad, 11 Februari 1925.

De Indische Courant, 5 Juni 1923

De Indische Courant, 16 Juni 1926

De Indische Courant, 17 November 1927

De Indische Courant, 24 April 1935

Het Nieuws van den Dag voor Nederlandsch-Indie, 11 Februari 1922

Het Nieuws van de Dag voor Nederlandesch-Indie, 7 Oktober 1931

Het Vaderland: Staat-en Letterkundig Nieuwsblad, 31 Maret 1926

Soerabaijasch Handelsblad, 26 Juni 1929

Soerabaijasch Handelsblad, 8 Januari 1930

Soerabaijasch Handelsblad, 8 Oktober 1931

Soeara Moehammadijah, Oktober 1923

Soeara Moehammadijah, Desember 1923 


\section{Buku dan Artikel}

Fauzia, Amelia. 2013. "Faith and the State: a History of Islamic Philantrophy in Indonesia”. Dissertation. Belanda: Brill's Southeast Asian Library.

Kartodirjo, Sartono. 2014. Pengantar Sejarah Indonesia Baru: Sejarah Pergerakan Nasional. Yogyakarta: Ombak.

Latief, Hilman. 2012. "Islamic Charities and Social Activism: Welfare, Dakwah and Politics in Indonesia”. Dissertation. Netherland: Leiden Universiteit.

.mm, Melayani Umat: Filantropi Islam dan Ideologi Kesejahteraan Kaum Modernis. Jakarta: Gramedia, 2010.

Mua'rif, “Tujuh Tokoh Pendiri Muhammadiyah”, dalam Basis, No. 01-02, Tahun Ke-59, 2011.

Muarif. 2012. Modernisasi Pendidikan Islam: Sejarah dan Perkembangan Kweekschool Moehammadijah 1923-1932. Yogyakarta: Suara Muhammadiyah.

Muhammad Syoedja'. Cerita tentang Kiyai Haji Ahmad Dahlan: Catatan Haji Muhammad Syoedja', tidak diterbitkan.

Purwanto, Bambang. "Capitalizing Charity in Indonesian Muslim Community: The History of PKU Muhammadiyah-Aisyiah Hospital”. Paper. International conference on "Indigenous Charities: Historical Studies of Institutions Across Culture”. Hongkong 6-7 November 2008.

Ricklefs, MC. 2005. Sejarah Indonesia Modern 1200-2004. Jakarta: Serambi.

Surjomiharjo, Abdurrachman. 2008. Kota Yogyakarta Tempo Doeloe. Jakarta: Komunitas Bambu.

Syoedja', Muhammad. Cerita tentang Kiyai Haji Ahmad Dahlan: Catatan Haji Muhammad Syoedja'. tidak diterbitkan.

Wadjdy, Farid dan Mursyid. 2007. Wakaf dan Kesejahteraan Ummat Filantropi Islam yang Hampir Terlupakan. Yogyakarta: Pustaka Pelajar.

Yuristiadhi, Ghifari. "Transformation of Charities by Islamic Social Movements In Yogyakarta, 1912-1931: A History of Islamic Wealth Management”. Makalah. $3^{\text {rd }}$ ASEAN International Conference on Islamic Finance di Semarang, 18-19 November 2015.

\section{Website}

"Sejarah", dalam www.rspkujogja.com.

"Sejarah", dalam www.bethesda.or.id.

"Jati diri dan Sejarah", dalam www.pantirapih.or.id.

www.muhammadiyah.org.

\section{Narasumber}

Abunda Faruq, mantan Direksi RS PKU Muhammadiyah (74) di Kauman, 6 Februari 2015.

Budi Setiawan, cucu Hadjid, murid langsung KH Ahmad Dahlan (59) di Wirobrajan, 24 Januari 2015. 